\title{
Gender Differences in Mathematics Performance in Trinidad and Tobago: Examining Affective Factors
}

\author{
Launcelot I. Brown \& Gibbs Y. Kanyongo \\ Duquesne University
}

\begin{abstract}
This study investigates gender differences in performance on the mathematics component on the Standard 3 National Assessment in Trinidad and Tobago. Of interest is whether there is a relationship between attitudinal differences regarding mathematics and student beliefs in their mathematical abilities and student gender classification. Results indicate that whereas girls performed better than boys on all categories and all skill areas on the test, the effect sizes were small. The results of a MANOVA with follow-up descriptive discriminant analysis also indicate that while boys and girls did not differ with regard to the perception of the school environment, educational values and goals, and general academic self-concept, they differ significantly on the persistence and mathematics self-concept factors. Girls tend to persist more, but hold lower mathematics self-concept than boys.
\end{abstract}

Keywords: persistence, mathematics self-concept, Caribbean

Despite some inconsistencies in results, most of the early studies on mathematics achievement found that boys, consistently scored higher than girls on a number of indicators of mathematical proficiency (Fennema \& Sherman, 1977; Kloosterman, 1988; Manning, 1998; Peterson \& Fennema, 1985; Randhawa, 1991, 1994). This study examines the phenomenon in the English speaking Caribbean, specifically Trinidad and Tobago, where girls consistently have outperformed boys, and has become a matter of concern for Caribbean governments and educators (Caribbean Education Task Force, 2000).

A review of the literature from the USA and other Western societies on gender and mathematics achievement has revealed an inconsistent relationship between gender and mathematics attainment during the early years of schooling. For example, in a 3-year longitudinal study conducted in the USA that examined the strategies that students in the lower primary grades (grade 1-3) utilized in solving mathematics problems, Fennema, Carpenter, Jacobs, Franke, and Levi (1998) did not find gender differences in the ability to solve mathematics problems in grade 3 (8-10 year olds). They found however significant differences in problem-solving strategies in which girls tended to employ "concrete solution strategies like modelling and counting, while boys tended to use more abstract solution strategies that reflected conceptual understanding" (Fennema \& Carpenter, 1998, p.4). However, Tapia and Marsh (2004) contend that up to 1994, measurable gender differences in mathematics scores are apparent only from age 13 and since that time, whatever gap existed seems to have disappeared.

Hanna (2003) contends similarly with regard to the disappearance of the gender gap, while Hyde et al. (1990) and Leahey and Guo (2001) extend this argument and caution against the assertion that there is an evident gender difference in mathematics achievement favouring males. Leahey and Guo (2001) further state that at the elementary level existing differences were not consistent across mathematics skill areas, and where differences existed, 
were small but in favour of girls. Nevertheless, they did confirm that at the secondary level, males exhibited a consistent but slightly superior performance in the areas of problem-solving (Hyde et al., 1990) and reasoning skill and geometry (Leahey \& Guo, 2001).

Brunner, Krauss and Kunter's (2007) examined the performance on mathematics items of students in Germany. In their study they compared gender differences in overall mathematics ability (which as they explain is the standard model commonly found in the literature), and specific mathematics ability, i.e., an ability that influences performance on mathematics items over and above general cognitive ability (p. 405). They found that girls slightly outperformed boys on reasoning ability, but on specific mathematics ability, boys had a significant advantage over girls.

Cooper and Dunne (2000) in their study of the influence of the socio-cultural background on students' interpretation of 'realistic' mathematical problems on the National Curriculum in England also found that the means for boys were higher than those for girls. Overall, they noted that 'service class' students - those from the higher socio-economic levels - exhibited superior performance on realistic items than students in the lower socio-economic categories. However, they also observed that boys achieved slightly better scores than girls on 'realistic' items (i.e. items to which they could relate, or were part of their experiences) in comparison to 'esoteric' items -- (i.e. items that were more abstract.)

More recent studies provide additional support for the above findings. For example, Williams, Wo and Lewis (2007) in their investigation of 5-14 year old students' progress in mathematics attainment in England indicated that in the early years of schooling, individual differences in mathematics attainment are difficult to establish. In extending the discussion, Neuville and Croizet (2007) in a study of 7-8 year olds conducted in France, found that when gender identity is salient, girls perform better than boys on easy problems. On the other hand, boys' performance on mathematics was not affected by gender identity. They were not subjected to stereotype threat that made negative assumptions about their mathematical ability, and so, they performed better on the more difficult problems. The study concluded that young girls are more susceptible to the salience of their stereotyped gender identity than boys.

An examination of the Fourth Grade data from the International Association for the Evaluation of Educational Achievement (IEA)'s Third International Mathematics and Science Study (TIMSS), to some extent, contrasts slightly with Leahey and Guo's (2001) findings. The TIMSS data show that in the majority of the participating countries boys attained higher mean scores in mathematics, however in only three countries - Japan, Korea and the Netherlands- were these means statistically significant at alpha $=.05$. The averages of all country means were: males $=535$ and females $=533$ (Mullis, Martin, Fierros, Goldberg \& Stemler, 2000) indicating that differences attributed to gender were minimal and random.

In an analysis of the OECD's 2000 Programme for International Student Assessment (PISA), Marks (2008), found that in most countries, "girls on average, have ... lower scores in mathematics than boys" and the average "across-country gender gap was 11 score points" in favour of boys (p.96). He further explains that while in 15 of the 31 countries the gender difference in mathematics was not significant, in three countries, the difference was a sizable 27 score points, and in another two, the gap was moderate. In only three countries did girls do better than boys but the difference was not statistically significant (p.96). Despite the 
consistency in the research, there remains a growing concern over the academic performance of boys, a concern which is echoed loudly in England (Gorard, Rees \& Salisbury, 1999; Office for Standards in Education (OFSTED), 1996; Younger, Warrington \& Williams, 1999) as evidenced from the running debate and commentaries in the BBC News (09/18/2003), and the mentoring programme for underachieving Afro-Caribbean boys implemented by the British Government (Odih, 2002).

From the above review, while there are slight inconsistencies in the findings, we can conclude that overall at the primary or elementary level, there is no significant difference in the mathematics performance of boys and girls. The differences only become noticeable at the secondary level where boys perform better than girls in geometry and on the more difficult mathematics items.

\section{Mathematics Achievement Patterns: The Trinidad and Tobago Contexts}

The concern over the gender differential in mathematics performance remains the subject of intense debate in the English-speaking Caribbean (Caribbean Education Task Force, 2000). Specific to Trinidad and Tobago, and in contrast to the literature coming out of the U.S. and Western Europe, Jules and Kutnick (1990), Kutnick and Jules (1988) found that girls perform better than boys on teacher-made tests at all ages between 8 and 16, across all curriculum areas and in all curriculum subjects. They achieve better results on the Secondary Education Assessment (SEA) taken in Standard.5 (Std. 5) (age 11-12) and also achieve better results on the Caribbean Secondary Education Certificate (CSEC), the Caribbean equivalent to the British GCSE, administered by the Caribbean Examinations Council (CXC), taken at age 1617 in Form 5 (Kutnick, Jules \& Layne, 1997; Parry, 2000).

Brown (2005) corroborates the above findings, at least for students in the lower primary school classes. In examining the performance of 7-9 year olds on the mathematics component of the 2000 Trinidad and Tobago National Test, he found that overall the mean achievement score of girls was higher than that of boys. Additionally, he found that the non-response to items was significantly greater for boys than girls, and a significantly greater number of boys than girls were in the lower tail of the distribution. In an attempt to determine whether the tests were biased in favour of girls, Brown and Kanyongo (2007) conducted differential item functioning (DIF) analysis on test items on the mathematics component of the 2004 National Test: Std. 1 (age 7-9). They found that though five of thirty items on the test significantly differentiated in favour of girls, in practical terms, the differences in item function were negligible and therefore could not explain the gender differential in performance on the test.

With regard to Kutnick et al. (1997) and Parry's (2000) observation of student performance on the CSCE, a review of the 2000-2002 CSEC ordinary level results for Trinidad and Tobago allows for alternative interpretations. The results showed that of the students taking mathematics at the general proficiency level, a greater percentage of boys than girls earned Grades I-III (Brown, 2005). This finding seems to give support to the claim that boys on average perform better in higher-level mathematics (Leahey \& Guo, 2001; Manning, 1998; Randhawa, 1991, 1994); however, it needs to be qualified by the fact that a greater percentage of girls take general proficiency level mathematics - the more rigorous course whereas more boys take basic level mathematics (Brown, 2005). 
Caribbean scholars have tried to understand this phenomenon and have offered a number of possible explanations. Miller (1994) frames his argument in the context of the historical marginalization of the black male in the Caribbean of which disinterest in education has been an inevitable outcome. Chevannes (2001) and Parry (2000) contend; while Conrad (1999) implies that the problem may be due to socialization practices and cultural expectations of gendered behaviour which for males conflict with the ethos of the school, but alternatively, encourage females to be academically successful. Figueroa (1997), on the other hand, posits that what the Caribbean has been witnessing is the result of the traditional independence of Caribbean women, and historic male privileging of which one consequence has been male educational underachievement. The explanations presented all seem plausible. However, with the possible exception of studies by Kutnick et al. (1997) and Parry (2000) which looked at classroom variables, they are yet to be tested.

In 2004-2005, the Trinidad and Tobago Ministry of Education (MOE) began collecting data that went beyond analysis of student performance on the National Tests. While the instrument did not address socio-cultural factors, it addressed affective factors that predict academic achievement. From the instrument, we extract items that examine student motivation, academic self-perception, emphases on the value and purpose of education, and perception of the school. Each of these factors has been found to be predictors of academic achievement in previous research. (Dweck \& Leggett, 1988; Marsh, 1992).

\section{Student Motivation, Academic Self-perception and Beliefs}

Dweck's Motivation Process Model (Dweck \& Leggett, 1988) posits that performance is impacted by an individual's belief about his or her ability (or lack thereof). This argument she frames within the concept of learning goals and performance goals. Students with high learning goal orientation are focused on the acquisition of new knowledge or competencies. They place an intrinsic value on knowledge, which is reflected in a desire to learn. Implicit to the desire to learn, is the willingness to make the effort to achieve their goal. As a result, they are more likely to persist with challenging material, responding with increased effort to master the material.

Performance oriented students, although also motivated to achieve, place greater emphasis on proving their competence (Grant \& Dweck, 2003). In the present competitive atmosphere of the school, this often means achieving a desired grade: not as a validation of their learning, but as validation of their ability. The conceptualization of ability as a reflection of one's performance (Burley, Turner \& Vitulli, 1999) creates the tendency to avoid material that could result in poor performance. They display what Dweck and Leggett (1988) refer to as 'helpless' response - low persistence when challenged by difficult material. The emphasis is on demonstrating one's competence and avoiding the appearance of incompetence (Ryan \& Deci, 2000, Lapointe, Legault \& Batiste, 2005).

Researchers have studied the motivational orientations and student academic selfperception from a variety of theoretical perspectives (Dweck \& Leggett, 1988; Heyman \& Dweck, 1992; Ryan and Deci, 2000; Ryan \& Patrick, 2001; Schommer-Aikens, Brookhart, Hutter \& Mau, 2000). A summary of the findings suggests a positive relationship between student motivation, self-esteem, academic engagement and academic achievement (Nichols, 
1996; Singh, Granville, \& Dika, 2002). Further, the literature shows that underlying motivation is the individual's beliefs - self theories - (Lepper \& Henderlong, 2000). It is this belief in one's ability and its relation to achievement that drives persistence. Therefore, with regard to this study, students who believe in their mathematics ability, and further believe that their ability is linked to their effort in learning mathematics are motivated to work harder and as a result achieve at a higher academic level.

But there are other factors both intrinsic and extrinsic to students that are related to their performance in mathematics. While we recognize that the classroom environment created by the teacher and other institutional variables are critical elements in student learning, we also recognize it is students' perception of the school and classroom environments that make these environmental factors powerful motivators or demotivators to their academic performance (Ireson \& Hallam, 2005; Ryan \& Patrick, 2001). Additionally, student attitude toward mathematics is highly correlated with achievement in mathematics (Ma, 1997; Ma \& Kishor, 1997). Their belief that mathematics is important to achieving their future goals results in greater effort to succeed in mathematics and as a result, higher achievement scores (Bouchey \& Harter, 2005). Therefore, students' scores on items that address these factors are expected to be related to their scores on the mathematics component on the national test.

As part of the growing interest in gender differential in academic performance that is evident at all levels and across disciplines in Trinidad and Tobago, this study seeks to determine whether students' attitude towards mathematics and students' beliefs in their mathematical abilities are related to the differential in mathematics attainment between boys and girls. Specifically the study asks:

1. Do mean achievement scores differ by gender on a Std. 3 (age 9-10) large-scale mathematics assessment in Trinidad and Tobago?

2. Is there a difference between boys and girls on their perception of school, their persistence when faced with academic challenges, their general academic self-concept and mathematics self-concept, and their educational values?

\section{Method}

\section{Trinidad and Tobago Education System: A Brief Review}

Trinidad and Tobago is a multi-ethnic, multi-religious society in which no area is exclusive to one ethnic or religious grouping. The education system is run by a central authority - the Ministry of Education (MOE). The country is divided into eight educational districts which, with the exception of Tobago which is predominantly of African descent, are representative of all socio-economic levels, ethnic and religious grouping in the country. Each educational district is headed by a School Supervisor III (SS III) assisted by SSII's responsible for secondary schools and SSI's responsible for primary schools. Early Childhood Care and Education is a separate department in the MOE. All educational policies and mandates emanate from the central office to the respective supervisory levels (Oplatka 2004). 
The public education system of Trinidad and Tobago comprises four levels: early childhood care and education (3-4 year olds), primary education (5-11/12 years) the secondary education (12-16/17 years) and the tertiary level. The public primary education system consists of 484 schools. Of this number, 30 percent are government-funded and managed non-religious schools. The remaining 70 percent are government-funded schools but managed by denominational boards representing Christian, Hindu and Muslim religious persuasions (MOE, 2001). Parents have the right to send their children to any school within their school district. Each primary school is divided into an infant department where students stay for two years (1st and 2nd year infants), and the primary level where students stay for five years - Standards (Std.) 1-5.

\section{Participants}

The participants were 561 public elementary school students from an educational district in northern Trinidad. The choice of the educational district was appropriate because its student population is representative of the student populations in the other six educational districts in Trinidad ensuring that the sample represented the demographic make-up of the country (See the-world-factbook). Sixteen students were removed before analysis due to failure to include the student identification code, leaving 545 students (girls $=253$, boys $=$ 292 , age range 8-10 with a mean of 9.53 years). Of these students, 226 identified themselves as Trinidadian of African descent, 201 of East Indian descent, 4 Chinese, 3 White and 100 Mixed. Eleven students did not indicate their racial/ethnic origin. However, it is important to point out that ethnicity is not a variable of interest in this study.

\section{Instruments}

The national test. Two sources provide the data for this study; student scores on the mathematics component of the Std. 3 National Test and their responses to items on the questionnaire to provide supplementary data.

The examination consisted of 25 items which fell into either of the following categories: Number: 11 items, Measurement and Money: 8 items, Geometry: 3 items, and Statistics: 3 items. The national exam tested the following competency (skill) areas: knowledge computation (KC), algorithmic thinking (AT), and problem solving (PS). Some items had multiple parts, with each part testing a different skill, whereas some items tested all three skills simultaneously (Table 1).

Items on the examination were dichotomously scored as either 1 for a correct response or 0 for an incorrect response, or polytomously scored as either 2 - correct, 1 -- partially correct or 0 -- incorrect.

The cut scores on the test separated students into the following four mastery levels:

- Level 1: Below Proficient. Score range 0-17.

- Level 2: Partially Proficient. Score range 18-29.

- Level 3: Proficient. Score range 30-39.

- Level 4: Advanced Proficiency. Score range 40-55. 
Table 1

Examination questions (items) by category and skill area

\begin{tabular}{lccccc}
\hline Category & \multicolumn{5}{c}{ Standard $3(n=45$ parts $)$} \\
\hline & $K C$ & $A T$ & $P S$ & No. Parts & Total Score \\
Number (11 items) & 9 & 8 & 4 & $\mathbf{2 1}$ & $\mathbf{2 4}$ \\
Measurement and money (8 items) & 7 & 5 & 4 & $\mathbf{1 6}$ & $\mathbf{1 9}$ \\
Geometry (3 items) & 1 & 1 & 1 & $\mathbf{3}$ & $\mathbf{5}$ \\
Statistics (3 items) & 1 & 3 & 1 & $\mathbf{5}$ & $\mathbf{7}$ \\
Entire exam & $\mathbf{1 8}$ & $\mathbf{1 7}$ & $\mathbf{1 0}$ & $\mathbf{4 5}$ & $\mathbf{5 5}$ \\
\hline
\end{tabular}

We consulted with a mathematics education expert to determine the cognitive demand of the items on the test. The majority of the items were at the procedural without connections, or memorization difficulty level as described by Stein, Grover and Henningsen (1996), and therefore, elicited low-level thinking and reasoning. Only four items were at the level of procedures with connections and had the potential to elicit high-level thinking (Stein et al., 1996). The following are examples of the types of items on the test.

Ruth had 7/8 of a kilogram of cheese.

She used $3 / 8$ of a kilogram to make pies.

How much cheese was left?

Answer
Mrs. Jack is teaching a lesson Measuring Distances to her Standard 3 class.

She teaches that $\mathbf{1 0 0}$ centimetres $=\mathbf{1}$ metre

Petrina used a tape marked in centimetres to measure the length of her classroom.

She got a measurement of 600 centimetres.

1. Write what Petrina must do to change the length of the classroom into metres.

2. The length of the classroom is metres

Figure 1. Examples of types of test items.

The questionnaire. Factor analysis was performed on the questionnaire to develop the five factors (Persistence, Academic self-concept, Values and Goals, School Environment, and Mathematics self-concept) that were used in this study as dependent variables. Because these five dependent variables were considered simultaneously, (with gender as the independent variable), we utilized the multivariate analysis of variance (MANOVA) procedure.

Although one of the assumptions for the use of factor analysis is that the data are measured on an interval scale, Kim and Mueller (1978) note that ordinal data may be used if the assignments of ordinal categories to the data do not seriously distort the underlying metric 
scaling. In a review of the literature on the use of data collected on Likert scales, Jaccard and Wan (1996) concluded that, for many statistical tests, rather severe departures from intervalness do not seem to affect Type I and Type II errors dramatically. Other researchers like Binder (1984) and Zumbo and Zimmerman (1993) also found the robustness of parametric coefficients with respect to ordinal distortions.

Additionally, we used the Principal Axis Factoring procedure as our method of extraction because it seeks the least amount of factors that account for the most amount of common variance for a given set of variables. We also employed oblique rotation because it often reflects the real world more accurately than orthogonal rotation since most real-world constructs are correlated. (See Fabrigar, Wegener, MacCallum and Strahan, 1999; and Preacher and MacCallum, 2003 for a detailed but non-technical discussion of the topic). The five constructs that we extracted in this study are correlated, another justification for using MANOVA with the five constructs as dependent variables.

The questionnaire comprised 50 items. Items 1 to 10 sought demographic information. Of the remaining forty items, twenty eight were variables of interest. These measured academic self-esteem, perception of school/classroom environment, relationship with teacher, goals and value of education, mathematics self concept and persistence on a 5-point scale anchored by 1 - disagree very much and 5 - agree very much. To test whether the items really measured the underlying dimensions of interest, we subjected the items to a Principal Axis Factoring with Oblique rotation, suppressing loadings on variables lower than .40. This yielded a six-factor solution. The sixth factor accounted for only an additional four percent of variance; therefore, five factors were specified. This resulted in the four items pertaining to student-teacher relationship loading on student perception of school/classroom creating the school environment factor. All other factors remained the same. Additionally, two of the items measuring academic self-concept yielded loading values less than .40 , and therefore, were deleted from the scale leaving 26 items to provide the data for the study. Two items addressed mathematics self-concept. These items consistently loaded together yielding loadings of .846 and .772 respectively (see Appendix).

Table 2

Eigenvalues and variance percentages and scale reliability values

\begin{tabular}{lcccc}
\hline Factors & Eigenvalues & \% of Variance & Cumulative \% & Cronbach's alpha \\
\hline Persistence & 7.397 & 28.449 & 28.449 & .85 \\
General self-concept & 2.953 & 11.359 & 39.808 & .80 \\
Math self-concept & 2.112 & 8.123 & 47.931 & .79 \\
Values and goals & 2.001 & 7.696 & 55.628 & .74 \\
School environment & 1.297 & 4.988 & 60.616 & .85 \\
\hline
\end{tabular}

Overall scale reliability: Cronbach's alpha $=.90$

On this sample, the five factors accounted for $60.62 \%$ of the variance in the set of variables with the first and second factors accounting for $28.45 \%$ and $11.36 \%$ of the variance. All factors yielded inter-item correlations $>.35$ with several correlations $>.70$. Inversely, matrices of partial correlations were very low supporting the presence of factors. The factors were: perception of school/classroom (8 items) e.g., "I am glad I go to this school," persistence (6 items) e.g. "When work is difficult I try harder," general academic self- 
concept," (6 items), e.g., "I can learn new ideas quickly in school," goals and values (4 items) e.g., "Doing well in school is one of my goals," and mathematics self concept (2 items) e.g., "I am good at mathematics." Internal consistency reliability for the entire instrument was .90. Table 2 shows the five sub-scales (factors) in the final instrument and their reliability values as well as the percentage of the variance they account for.

\section{Procedure}

Using the student ID numbers, student scores on the mathematics assessment were paired with their responses on the supplementary data questionnaire. Before conducting the statistical analyses, all appropriate statistical assumptions were tested. The assumptions homogeneity of variance and covariance, and linearity were tenable. As expected, all factors displayed negative skewness. To reduce skewness and kurtosis, and by doing so, achieve a better approximation to a normal distribution, variables displaying moderate to substantial skewness and kurtosis were subjected to either a square root or logarithmic transformation. Despite these transformations, some variables still yielded skewness and kurtosis slightly greater than $1,(\mathrm{Sk}=1.5$ and $\mathrm{K}=1.27)$. However, with $\mathrm{N}>500$, and pairwise within group scatterplots revealing no discernible patterns, these small deviations from normality should not present any concerns. Tests for multivariate outliers identified five cases with values above the criterion, $\chi^{2}(\mathrm{df}, 4)=18.47, p=.001$. To remove their undue influence, these cases were deleted from the sample. Further screening identified an additional case. This case was removed resulting in a final sample $\mathrm{n}=539$.

\section{Data Analysis}

First, to investigate gender differences on the mathematics assessment, independent t-tests were performed. Second, to determine the extent to which the male and female examinees differed on the five constructs, a univariate analysis of variance (ANOVA) was conducted on the school environment factor because this was not correlated with the other factors. Third, a multivariate analysis of variance (MANOVA) was performed on the four correlated factors (persistence, mathematics self-concept, general self-concept, and goal values) as dependent variables. Descriptive discriminant analysis was conducted as follow-up to a significant multivariate $F$ to determine which variable or variables contributed most to differences between the groups. We used effect size to measure the magnitude of the difference between the mean score for boys and girls on each mathematics category tested. Effect size was obtained by dividing the difference between boys' and girls' mean by the pooled withingender standard deviation. According to (Cohen, 1992), effect sizes of less than .20 are considered small and represent small practical significance; effect sizes between .20 and .50 are medium and represent moderate practical significance. Effect sizes greater than .50 are considered large.

\section{Results}

The first step in this study sought to determine whether boys and girls differed in performance on a Standard 3 large-scale mathematics assessment in Trinidad and Tobago. To make this determination, we performed an independent $\mathrm{t}$-test between the means of the two 
samples for each category and skill area. Table 3 shows the means and the effect sizes of the differences between the two samples for each category, cognitive demand level and skill area. In the table, we also report standard error of the means (SEM) to provide an index of the sampling variability of the means. The results indicate that while girls achieved higher mean scores in all categories, difficulty levels and all skill areas on the test, the differences between boys and girls were statistically significant at $p<.01$ for only two categories; number and statistics. Statistical differences were also found for the three skill areas: knowledge and computation, algorithmic thinking and problem solving, and on procedural items and those that demanded higher-level cognitive demand. The two samples also differed on the entire exam, $t(536)=-3.26, p=.001, d=.28$.

Table 3

Mean normal curve equivalent(nce) scores of the test categories, difficulty levels and skills for male and female examinees

\begin{tabular}{|c|c|c|c|c|c|c|}
\hline \multirow[t]{2}{*}{ Category } & \multicolumn{2}{|c|}{$\operatorname{Boys}(n=289)$} & \multicolumn{2}{|c|}{ Girls $(n=250)$} & \multirow{2}{*}{$\frac{\text { Sig. }}{p}$} & \multirow{2}{*}{$\frac{\text { Effect Size }}{D}$} \\
\hline & Mean & $S E M$ & Mean & $S E M$ & & \\
\hline Number & 52.20 & \pm 1.17 & 57.83 & \pm 1.22 & .001 & .29 \\
\hline Measurement and money & 52.73 & \pm 1.18 & 56.48 & \pm 1.26 & .031 & .19 \\
\hline Geometry & 52.89 & \pm 1.20 & 56.04 & \pm 1.22 & .068 & .16 \\
\hline Statistics & 50.53 & \pm 1.16 & 56.87 & \pm 1.23 & .002 & .27 \\
\hline \multicolumn{7}{|c|}{ Skill Area } \\
\hline Knowledge and computation & 51.01 & \pm 1.16 & 57.44 & \pm 1.24 & .000 & .33 \\
\hline Algorithmic thinking & 53.81 & \pm 1.11 & 57.92 & \pm 1.24 & .013 & .21 \\
\hline Problem-solving & 53.60 & \pm 1.22 & 58.41 & \pm 1.25 & .006 & .24 \\
\hline \multicolumn{7}{|c|}{ Cognitive Demand } \\
\hline Low memorization & 49.08 & \pm 1.26 & 51.04 & \pm 1.31 & .754 & .09 \\
\hline Low procedural & 46.55 & \pm 1.25 & 53.92 & \pm 1.28 & .000 & .35 \\
\hline High procedural & 48.00 & \pm 1.21 & 52.27 & \pm 1.35 & .019 & .20 \\
\hline Entire exam & 52.75 & \pm 1.14 & 58.20 & \pm 1.22 & .001 & .28 \\
\hline
\end{tabular}

According to McCartney and Rosenthal (2000), practical significance depends upon the research and the empirical literature contexts, and as stated by Light, Singer \& Willett (1990), "only the researcher can judge if an effect is large enough to be important" (p.195). An examination of comparable studies conducted in other countries, indicated that our results were consistent with what other researchers have found. For example, Skaalvik (2004) conducted a study on gender differences and mathematics self-concept, performance expectation and motivation among Norwegian students. The results indicated a medium effect size (.36) in favor of female students among ninth graders. More importantly, an effect size of 0.2 while it may be considered small may in fact belie the magnitude of its impact. To quote Cooper and Dunne (2000), "in the world of educational practice where decisions are often taken on the basis of thresholds being achieved or not by children, differences of this size can have large effects" (p. 94). As a matter of fact, Hattie (1992) evidencing a synthesis of 134 meta-analyses posits that the effect of innovations on achievement is 0.4 standard deviation and on affective outcomes 0.2 standard deviation. For this study, we consider all effect sizes equal to or greater than 0.2 standard deviation to be of practical importance. 
The second question investigated whether boys and girls differ in their perception of school, on their persistence when faced with academic challenges, on their general academic self-concept, on their mathematics self-concept and on their educational values. Gender differences on perception of the school environment were non-significant. However, the MANOVA results indicate that there was a significant difference between the two groups, Wilks' Lambda $=.83, F(4,534)=27.76, p=.000, \eta^{2}=.17, p<.001$, reflecting a moderate association between gender and the combined dependent variables. Of interest, therefore, is the extent to which the four factors, now the independent variables, contribute to explaining the separation of the groups based on their gender classification.

Table 4

Pooled within-groups correlations coefficients and standardized canonical discriminant function coefficients

\begin{tabular}{lcc}
\hline Factors & $\begin{array}{c}\text { Correlation } \\
\text { coefficients }\end{array}$ & $\begin{array}{c}\text { Standardized function } \\
\text { coefficients }\end{array}$ \\
\hline Persistence & .69 & 1.01 \\
Math self-concept & -.48 & -.59 \\
Educational values and goals & .12 & .05 \\
General self-concept & -.06 & -.34 \\
\hline
\end{tabular}

To answer this question, descriptive discriminant analysis was performed. The correlation between the predictor variables and the discriminant function indicate that persistence $(\mathrm{r}=.69)$ accounting for $48 \%$ of the variance shared with the discriminant function, and mathematics self-concept ( $\mathrm{r}=-.48$ ) accounting for $23 \%$ of the variance, contributed the most to the linear discriminant function that maximizes the separation of girls and boys (Table 4).

An examination of the means shows that girls scored significantly higher than boys on persistence while the opposite occurred on mathematics self-concept (Table 5).

Table 5

Descriptive statistics for male and female examinees on the subscales

\begin{tabular}{lcccccc}
\hline Factors & \multicolumn{2}{c}{ Boys $(n=289)$} & \multicolumn{2}{c}{ Girls $(n=250)$} & Sig. & Effect Size \\
\hline & Mean & SD & Mean & SD & $P$ & $d$ \\
Persistence & 3.80 & .73 & 4.21 & .57 & .00 & .63 \\
General self-concept & 4.04 & .64 & 4.00 & .65 & $n s$ & .06 \\
Math self-concept & 3.54 & .71 & 3.22 & .76 & .00 & .43 \\
Values and goals & 3.45 & .72 & 3.53 & .78 & $n s$ & .09 \\
School environment & 4.29 & .67 & 4.38 & .64 & $n s$ & .14 \\
\hline
\end{tabular}

\section{Conclusions and Implications}

These results confirm the findings in the Trinidad and Tobago literature that there exists a gender differential in mathematics performance in favour of girls. While the reported effect sizes are small to moderate, this does not translate to mean the impact on achievement is not important (Cooper and Dunne, 2000). This continuing differential has the potential to negatively impact the future academic and as a result, employment opportunities of boys. This is because the gap in performance between the sexes unless addressed, has implications for 
later student placement at the secondary education level. Although in Trinidad and Tobago, all students are guaranteed secondary education, in common with the other Caribbean islands, getting into one's school of choice is based on academic performance on some national assessment for secondary education taken at age 11-12 in Std. 5.

The consistency of the findings across the various studies at different age levels highlights a discomforting reality; a reality which is not unique to Trinidad and Tobago but, as noted in the report of the Caribbean Education Task Force (2000), is present in the Anglophone Caribbean. However, the issue of male academic underperformance may not be exclusive to the Caribbean. The fact that the British government has targeted young Afro-Caribbean males to be the recipient of their intervention programme (Odih, 2002) strongly suggests that this population also presents a critical concern and challenge for the British education system. It is possible that findings on the Trinidad and Tobago sample may be very relevant to the British Afro-Caribbean student population.

While this study does not attempt to address causation, it does present some interesting findings. We expected to see girls display significantly higher means on all the dependent variables. The results did not support this hypothesis. Girls did not differ significantly from boys in their perception of the school environment, on emphasis placed on educational goals, or in their general academic self-concept. The significant findings were on the level of persistence and mathematics self-concept. The data indicate that the girls in our sample display moderate and significantly higher levels of persistence than boys; alternatively, boys, although with less impact, tend to be more confident of their mathematics ability. This latter finding concurs with that of Rech (1994) who on a sample of 251 African American students ages 10-11 and 15 years; also found that scores for boys were significantly higher on selfconcept and enjoyment of mathematics.

The finding in favour of boys was surprising, especially in the Caribbean context, a culture known for the traditional independence of its women (Figueroa, 1997) and one in which girls excel academically and consistently outperform boys in all academic areas (Jules \& Kutnick, 1990; Kutnick \& Jules, 1988). Whereas existing differences on perception of the school and classroom environments, and global academic self-concept were random, we see what appears to be a gendered pattern beginning to emerge with regard to mathematics selfconcept. Interestingly, even as the girls in this sample place greater emphasis on the importance of doing well in school, striving to get good grades, and the importance of mathematics as a subject, boys were more prepared to indicate that they like mathematics and they were good at it. This occurs, even as more girls than boys take the more challenging mathematics classes at the secondary level (Brown, 2005) and lends support to Dweck's assertion that even as girls do better than boys in mathematics, they are more prone to doubt their mathematics abilities.

While there are studies that address issues related to male underachievement within the larger minority groups in the U.S. (Noguera, 2003) and Britain (Odih, 2002), there is little empirical evidence with regard to gender differences on factors that predict academic achievement within those minority groups. It would be interesting to ascertain whether these findings would be similar in those minority groups. If the findings are similar, then researchers would need to examine the effects of persistence that allow girls to significantly outperform boys on mathematics assessments, despite scoring lower on mathematical self- 
concept. This knowledge could be critically important for, in the same way mathematics education researchers aggressively addressed the issue of gendered expectation as it related to female underperformance in mathematics, researchers could adopt a similar effort to address the issue among males in the Caribbean and minority communities in Britain and the U.S. We do acknowledge that the factors cited in the literature of the western more developed societies with regard to female mathematics performance (See the reports of the AAUW) may not pertain to mathematics performance among Caribbean males. However, we think this is an area in need of further investigation especially as mathematics, wrongly or rightly, (Cooper \& Dunne, 2000) is considered the pre-eminent discipline in the area of academics.

One of the limitations to this study is that although the items that comprise the scale seem grounded in the literature, the construct validity of the scale has never been tested. Therefore, despite the high internal consistency reliability, this fact limits the extent to which we can definitively say that girls persist more than boys and boys have higher mathematical selfconcept than girls. Nevertheless, it is plausible to argue that these data suggest that girls tend to be higher on persistence but display lower mathematics self-concept than boys. However, as the Trinidad and Tobago Ministry of Education and other Caribbean education ministries continue to refine their instruments, we foresee future studies drawing more definitive conclusions.

We are not aware of any studies in the Caribbean literature that has examined quantitatively psycho-social factors in an attempt at further understanding the gender differential in academic performance, and have been challenged to find similar studies with a focus on minority groups in Western more developed countries. In this regard, this study adds to the ongoing search for solutions to the performance differential in Trinidad and Tobago and the wider English-speaking Caribbean, and hopefully encourages similar studies in other countries experiencing similar phenomena.

\section{References}

American Association of University Woman [AAUW] (2010). Breaking barriers for women and girls. Retrieved January 22, 2010 from http://www.aauw.org.

Binder, A. (1984). Restrictions on statistics imposed by method of measurement: Some reality, some myth. Journal of Criminal Justice, 12, 467-481.

Bouchey, A. H., \& Harter, S. (2005). Reflected appraisals, academic self-perceptions, and math/science performance during early adolescence. Journal of Educational Psychology, 97(4), 673-686.

Brown, L. I. (2005). Gender and academic achievement in math: An examination of the math performance data on seven to nine year olds in Trinidad and Tobago. Caribbean Curriculum, 12, 37-56.

Brown, L. I., \& Kanyongo, G. Y (2007). Differential item functioning and male-female differences in a large-scale mathematics assessment in Trinidad and Tobago. Caribbean Curriculum, 14, 49-71.

Brunner, M., Krauss, S., \& Kunter, M. (2007). Gender differences in mathematics: Does the 
story need to be rewritten? Intelligence, 36(5), 403-421.

Burley, R. C., Turner, L. A., \& Vitulli, W, F. (1999). The relationship between goal orientation and age among adolescents and adults. Journal of Genetic Psychology, 160, 84-88.

Chevannes, B. (2001). Learning to be a man: Culture, socialization and gender identity in five Caribbean communities. Mona, Jamaica: University Press.

Cohen, J. (1992). A power primer. Psychological Bulletin, 112, 155-159.

Conrad, D. A. (1999). Educational leadership and the ethic of care: The experiences of four women educators of Trinidad and Tobago. Unpublished doctoral dissertation. Virginia Polytechnic Institute and State University, Blacksburg, Virginia, USA.

Cooper, B., \& Dunne, M. (2000). Assessing children's mathematical knowledge: social class, sex and problem-solving. Buckingham: Open University press.

Dweck, C. S., \& Leggett, E. L. (1988). A social-cognitive approach to motivation and personality. Psychological Review, 95, 256-273.

Fabrigar, L. R., Wegener, W. T., MacCallum, R. C., \& Strahan, E. J. (1999). Evaluating the use of factor analysis in psychological research. Psychological Methods, 4(3), 272-299.

Fennema, E., Carpenter, T. P. (1998). New perspectives on gender differences in mathematics: An introduction. Educational Researcher, 27, 4-5

Fennema, E., Carpenter, T. P., Jacobs, V. R., Franke, M. L., \& Levi, L. W. (1998). A longitudinal study of gender differences in young children's mathematical thinking. Educational Researcher, 27, 6-11.

Fennema, E., \& Sherman, J. A. (1977). Sex-related differences in mathematics achievement, spatial visualization and sociocultural factors. American Educational Research Journal, $14,51-71$.

Figueroa, M. (1997, November). Gender differentials in educational achievement in Jamaica and other Caribbean territories. Paper presented at the Conference on Intervention Strategies to Address Male Underperformance in Primary and Secondary Education. Port of Spain, Trinidad and Tobago.

Gorard, S., Rees, G., \& Salisbury, J. (1999). Reappraising the apparent underachievement of boys at school. Gender and Education, 11, 441-454.

Grant, H., \& Dweck, C. (2003). Clarifying achievement goals and their impact. Journal of Personality and Social Psychology, 85, 541-553.

Halpern, D. F., (2000). Sex differences in cognitive abilities ( $3^{\text {rd }}$ ed.) Mahwah: NJ. Lawrence Erlbaum Associates.

Hattie, J. (1992). Measuring the effects of schooling. Australian Journal of Education, 36(1), $5-13$.

Heyman, G. D., \& Dweck, C. S. (1992). Achievement goals and intrinsic motivation: Their relation and their role in adaptive motivation. Motivation and Emotion, 231-247. 
Hyde, S. J., Fennema, E., \& Lamon, S. J. (1990). Gender differences in mathematics performance: A meta-analysis. Psychological Bulletin, 107(2), 139-155.

Ireson, J., \& Hallam, S. (2005). Pupils' liking for school: Ability grouping, self-concept and perception of teaching. British Journal of Educational Psychology, 75, 297- 311.

Jaccard, J., \& Wan, C. K. (1996). LISREL approaches to interaction effects in multiple regression. Thousand Oaks, CA: Sage Publications.

Jules, V., \& Kutnick, P. (1990). Determinants of academic success within classrooms in Trinidad and Tobago: Some personal and systemic variables. Educational Studies, 16, 217-235.

Jae-On, K., \& Mueller, C. W. (1978). Introduction to factor analysis: What it is and how to do it. Thousand Oaks, CA: Sage Publications, Quantitative Applications in the Social Sciences Series, No. 13.

Jules, D., Miller, E., \& Armstrong, A. L. (2000). Education strategy: Report of the Caribbean Education Task Force. Washington, D.C.: Caribbean Education Task Force, World Bank, Education Advisory Service.

Kloosterman, P. (1988). Self-confidence and motivation in mathematics. Journal of Educational Psychology, 80, 345-351.

Kutnick, P., \& Jules, V. (1988). Antecedents affecting science achievement scores in classrooms in Trinidad and Tobago. International Journal of Educational Development, $8,306-314$

Kutnick, P., Jules, V., \& Layne, A. (1997). Gender and school achievement in the Caribbean: Serial No. 21. London: Department for International Development.

Lapointe, J. M., Legault, F., \& Batiste, S. J. (2005). Teacher interpersonal and adolescents' motivation in mathematics: A comparison of learning disabled, average, and talented students. International Journal of Educational Research, 43, 39-54.

Leahey, E., \& Guo, G. (2001). Gender differences in mathematical trajectories. Social Forces, 80, 713-732.

Lepper, M. R., \& Henderlong, J. (2000). The little engine that had an incremental theory: an essay review of self-theories. Human Development, 43, 186-190.

Light, R.J., Singer, J.D. \& Willet, J.B. (1990). By design: Planning research in higher education. Cambridge, MA: Harvard University Press.

Ma, X., \& Kishor, N. (1997). Assessing the relationships between attitude toward mathematics and achievement in mathematics; a meta-analysis. Journal of Research in Mathematics Education, 28, 26-47.

Ma, X. (1997). Reciprocal relationships between attitude toward mathematics and achievement in mathematics. Journal of Educational Research, 90, 221-229.

Manning, M. (1998). Gender differences in young adolescents' mathematics and science achievement. Childhood Education, 168-171. 
Marsh, H. W. (1992). Content specificity of relation between academic achievement and academic self-concept. Journal of Educational Psychology, 84, 35-42.

Marks, G. N. (2008). Accounting for the gender gaps in student performance in reading and mathematics: evidence from 31 countries. Oxford Review of Education, 34(1), 89-109.

McCartney, K., \& Rosenthal, R. (2000). Effect size, practical importance, and social policy for children. Child Development, 71(1), 173-180.

Miller, E. (1994). Marginalization of the black male: Insights from the development of the teaching profession $\left(2^{\text {nd }} e d\right.$.). Jamaica: University of the West Indies, Canoe Press.

Mullis, I. V., Martin, M. O., Fierros, E. G., Goldberg, A. L., \& Stemler, S. E. (2000). Gender differences in achievement: IEA's Third International Mathematics and Science Study (TIMSS). Boston College, MA: TIMSS International Study Center.

Nichols, J. (1996). The effects of cooperative learning on student achievement and motivation in a high school geometry class. Contemporary Educational Psychology, 467-476.

Neuville, E. \& Croizet, J. (2007). Can salience of gender identity impair math performance among 7-8 years old girls? The moderating role of task difficulty. European Journal of Psychology of Education, 22, 307-316.

Noguera, P. (2003). The problem with black boys: The role and influence of environmental and cultural factors on the academic performance of African American males. Urban Education, 38, 431-459.

Odih, P. (2002). Mentors and role models: masculinity and the educational 'underachievement' of young Afro-Caribbean males. Race Ethnicity and Education, 5(1), 91-105.

Oplatka, I. (2004). The principalship in developing countries: Context, characteristics and reality. Comparative Education, 40(3), 428-448.

Parry, O. (2000). Male underachievement in high school education in Jamaica, Barbados, and St. Vincent. Kingston, Jamaica: Canoe Press.

Peterson, P., \& Fennema, E. (1985). Effective teaching, student engagement in classroom, and sex- related differences in learning mathematics. American Educational Research Journal, 22, 309-335.

Preacher, K. J., \& MacCallum, R. C. (2003). Repairing Tom Swift's electric factor analysis machine. Understanding Statistics, 2(1), 13-43.

Randhawa, B. S. (1994). Self-efficacy in mathematics, attitudes, and achievement of boys and girls from restricted samples in two countries. Perceptual and Motor Skills, 1011-1018.

Randhawa, B. S. (1991). Gender differences in academic achievement: A closer look at mathematics. The Alberta Journal of Educational Research, XXXVII, 241-257.

Rech, J. F. (1994). A comparison of the mathematics attitudes of black students according to grade level, gender, and academic achievement. Journal of Negro Education, 63(2), 212220. 
Ryan, M. A., \& Deci, E. L. (200). Intrinsic and extrinsic motivations: Classic definitions and new directions. Contemporary Educational Psychology, 25, 54-67.

Ryan, M. A., \& Patrick, H. (2001). The classroom social environment and changes in adolescents'motivation and engagement during middle school. American Educational Research Journal, 38, 437-460.

Schommer-Aikens. M., Brookhart, S., Hutter, R., \& Mau, W. (2000). Understanding middle school students' beliefs about knowledge and learning using a multidimensional paradigm. Journal of Educational Research, 94, 120-127.

Singh, K., Granville, M., \& Dika, S. (2002). Mathematics and science achievement: Effects of motivation, interest, and academic engagement. The Journal of Educational Research, 95(6), 323-332.

Skaalvik, S. (2004). Gender differences in math and verbal self-concept, performance expectation and motivation. Sex Roles: A Journal of Research, 3, 241-252.

Stein, M. K., Grover, B. W., \& Henningsen, M. (1996). Building student capacity for mathematical thinking and reasoning: An analysis of mathematical tasks used in reform classrooms. American Educational Research Journal, 33(2), 455-488.

Tapia, M., \& Marsh G. E.II (2004, Summer). The relationship of math anxiety and gender. Academic Exchange Quarterly, 8(2), 130-135.

The World Fact-book. Retrieved January 22, 2010 from https://www.cia.gov/library/publications/the-world-factbook/geos/td.html.

Trinidad and Tobago Ministry of Education. (2004). CXC O' Level General Proficiency results by subjects and grades obtained, 2000, 2001, 2002. Division of Educational Research and Evaluation, Port of Spain, Trinidad and Tobago.

Trinidad and Tobago Ministry of Education. (2001). Summary of Public Primary Schools in Trinidad and Tobago. Port-of-Spain: Trinidad and Tobago.

Williams, J., Wo, L., \& Lewis, S. (2007). Mathematics progression 5-14: Plateau, curriculum/age and test year effects. Research in Mathematics Education 9(1), 127-142.

Younger, M., Warrington, M., \& Williams, J. (1999). The gender gap and classroom interactions: Reality and rhetoric? British Journal of Sociology in Education, 20, 325-341.

Zumbo, B. D., \& Zimmerman, D. W. (1993). Is the selection of statistical methods governed by level of measurement? Canadian Psychology, 34, 390-399.

\section{Authors}

Launcelot I. Brown, PhD, Duquesne University, Pittsburgh, PA, USA; brownli@duq.edu

Gibbs Y. Kanyongo, PhD, Duquesne University, Pittsburgh, PA, USA; e-mail: kanyongog@duq.edu 
Appendix - Communalities and Factor Loadings

\begin{tabular}{|c|c|c|}
\hline Factors and Items & Communalities & Loadings \\
\hline \multicolumn{3}{|l|}{ Factor 1: Persistence } \\
\hline Don't give up easily & .512 & -.776 \\
\hline Work until succeed & .545 & -.692 \\
\hline Keep trying until I understand & .545 & -.808 \\
\hline Work hard at school work & .532 & -.624 \\
\hline Do all school work & .504 & -.613 \\
\hline Try harder when work difficult & .575 & .688 \\
\hline \multicolumn{3}{|l|}{ Factor 2: Academic Self-Concept } \\
\hline I am intelligent & .413 & .668 \\
\hline Learn new ideas quickly & .370 & .626 \\
\hline I am smart & .490 & .645 \\
\hline Learn new things easily & .405 & .546 \\
\hline School work is easy & .361 & .559 \\
\hline Understand difficult work & .429 & .523 \\
\hline \multicolumn{3}{|l|}{ Factor 3: Values and Goals } \\
\hline Want good marks & .473 & .742 \\
\hline Doing well important for future & .464 & .769 \\
\hline Doing well an important goal & .430 & .603 \\
\hline Math is very important & .463 & 678 \\
\hline \multicolumn{3}{|l|}{ Factor 4: School Environment } \\
\hline Classes interesting & .527 & -.715 \\
\hline Glad I go to this school & .532 & -.717 \\
\hline This is a good school & .605 & -.728 \\
\hline Relate well with teachers & .533 & -.580 \\
\hline Like teachers & .474 & -.683 \\
\hline Teachers make learning interesting & .501 & -.613 \\
\hline Teachers care & .464 & -.631 \\
\hline I like this school & .622 & -.752 \\
\hline \multicolumn{3}{|l|}{ Factor 5: Math Self-Concept } \\
\hline I like math & 672 & .866 \\
\hline Good at math & .798 & .778 \\
\hline
\end{tabular}

Extraction method: Principal axis factoring with oblique rotation. 